\title{
Three-item loneliness scale: psychometric properties and normative data of the Spanish version
}

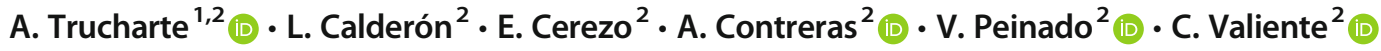 \\ Accepted: 11 July 2021 / Published online: 16 July 2021 \\ (C) The Author(s), under exclusive licence to Springer Science+Business Media, LLC, part of Springer Nature 2021
}

\begin{abstract}
Loneliness is a common social phenomenon across countries with negative effects in health. Thus, the measurement of loneliness is of paramount importance. The Three-Item Loneliness Scale (TILS) was designed to be used in large-population surveys as a quick measure of loneliness. The aim of this study is to provide a Spanish validation of the TILS. A representative sample of the Spanish population $(N=1951)$ was used. We analysed the psychometric properties, factor structure, and distribution demographics characteristics of the Spanish TILS. Analyses showed differences regarding age, gender, educational level, employment status, household composition and annual gross income in line with previous literature. The confirmatory factor analysis revealed a unifactorial structure, with significant moderate correlations between the TILS and depression, anxiety, paranoia and wellbeing, and mild significant correlations with belongingness and mistrust. The internal consistency of the Spanish TILS was good $(\alpha=0.82)$. Our study indicates that the TILS is a valid and reliable measure of loneliness in the Spanish population. Loneliness is a modern epidemic and a precursor of mental and health problems that reduced the quality of life. Therefore, it is important to have reliable measures of this phenomenon.
\end{abstract}

Keywords Loneliness $\cdot$ Social isolation $\cdot$ Validation $\cdot$ Psychometric characteristics

\section{Introduction}

Human beings have survived and developed into complex social groups, therefore, people need social connections and there is a tendency to dysregulate when these connections are lost or unavailable (Haworth et al., 2015). In this sense, it is important to distinguish between loneliness and social isolation. Loneliness is often defined as a subjective experience that causes distress over the absence of social contact, belonging or a sense of being alienated, while social isolation refers to the lack of social contact that can be objectively quantified (e.g., living alone) (Beutel et al., 2017; Mushtaq et al., 2014). Although social isolation and loneliness are different concepts, they are related, as social isolation feeds and intensifies feelings of loneliness (Meltzer et al., 2013). In fact, feelings of loneliness imply a discrepancy between what the person

A. Trucharte

almutruc@ucm.es

1 School of Psychology, Universidad Complutense, Campus de Somosaguas, 28223 Madrid, Spain

2 Department of Clinical Psychology, Complutense University of Madrid, Madrid, Spain would like and what they actually have in their relationships (Peplau \& Perlman, 1982). Nowadays, there is a general consensus that loneliness in older adults is a major public health problem (Berg-Weger \& Morley, 2020). Social isolation and loneliness are associated with an increase of mortality and with a reduced quality of life and well-being (Holt-Lunstad et al., 2015; Musich et al., 2015).

Unfortunately, loneliness has become a widespread social phenomenon (Igarashi, 2019). Population surveys in Europe have found that $4.6 \%$ of the population showed high levels of loneliness and $16.4 \%$ have showed moderate levels of loneliness (Lasgaard et al., 2016). Research on loneliness throughout our lifetime has found that it increases in late adolescence, decreases gradually during adulthood and increases in late adulthood (Luhmann \& Hawkley, 2016). Likewise, large surveys have found a U-shaped distribution, in which adolescence, emerging adulthood and old age had the highest levels of loneliness (Lasgaard et al., 2016). Specifically, in Spain the prevalence of frequent feelings of loneliness has been estimated at $4.4 \%$ for individuals under 30 years, $6.5 \%$ for individuals between 30 and 59 years, and $11.5 \%$ for those above 60 years (Yang \& Victor, 2011).

In addition to age, there are several sociodemographic and economic factors significantly associated with loneliness 
(Beutel et al., 2017; Vozikaki et al., 2018). Meta-analyses studying gender differences associated to loneliness have shown mixed results (Maes et al., 2019). Lower socioeconomic status has also been linked to loneliness (Algren et al., 2020). For instance, in a large morbidity survey in Denmark, Algren et al. (2020) have found that loneliness has been associated with health-risk behaviour in deprived neighbourhoods. In relation to living situations, the main predictor of loneliness is living alone rather than marital status (Berg-Weger \& Morley, 2020). Moreover, living with children is associated with less loneliness (Steed et al., 2007).

Lack of social support and loneliness have been associated with many negative physical and psychological consequences (Valtorta et al., 2016; Wang et al., 2018). A meta-analysis conducted by Erzen and Çikrikci (2018) suggested that loneliness is a significant predictor of depression, an association that remains stable across time (Victor \& Yang, 2012). In addition, Beutel et al. (2017) showed that loneliness was associated with generalised anxiety after controlling for demographic variables. The impact of loneliness on other mental health problems has been researched less (Lim et al., 2016), but there is a growing interest into the role of loneliness in disorders such psychosis (Chau et al., 2019). There is some evidence indicating that the relationship between loneliness and paranoia is mediated by the lack of interpersonal trust (Lamster, Lincoln, et al., 2017a). Furthermore, current models of paranoia stress the role of the sense of belonging (McIntyre et al., 2018) and of social identity (Greenaway et al., 2019), pointing out that these social constructs can be protective factors.

Given that loneliness is based on a subjective emotional experience (Lim \& Kua, 2011), self-reported measures are the most suitable to evaluate it and, given its significance for health, it is pivotal to have validated tools to measure it throughout life.

One of the most widely used questionnaires to evaluate loneliness is The Revised UCLA Loneliness Scale (Russell et al., 1978). The main limitation of UCLA-R is its length, which makes it difficult to use in large-scale studies (Hughes et al., 2004). For this reason, the Three-Item Loneliness Scale (TILS) was created using the UCLA-R items with the highest loadings in the loneliness factor. The three items selected have been shown to have good internal consistency and to be reliable (Hughes et al., 2004). Although there is some Spanish validations in samples of older adults for the UCLA-R (Sancho et al., 2020), the TILS has only been validated with American and Japanese populations (Hughes et al., 2004; Igarashi, 2019). Thus, it is appropriate to have a Spanish validation in a large representative sample. Therefore, the aim of this study is to analyse the psychometric properties and normative values of a Spanish adaptation of the TILS in a nationally representative sample. For this purpose, we used a TILS version translated into Spanish, generated by a bilingual specialist, then back-translated into English by another translator. The back-translated version was compared with the original TILS to check for complete correspondence (see Table 1).

\section{Methods}

The present study is part of a larger longitudinal project aiming to study the psychological consequences of the COVID-19 pandemic in the adult general population (for more information, see (https://osf.io/2y45r).

\section{Participants}

The respondents were participants of an online research panel using stratified quota sampling to ensure that the sample characteristics were representative of the Spanish population. Participants were aged 18 or older and completed an online survey via Qualtrics (https://www.qualtrics.com) at two different time points $(\mathrm{T} 1=7-14$ April 2020; T2 $=7-11$ May 2020). The average time to complete the survey was $42.5 \mathrm{~min}$ at $\mathrm{T} 1$ and $26.2 \mathrm{~min}$ at $\mathrm{T} 2$. After removing invalid surveys, the final sample was $N=1951$ at T1 and $N=1628$ at T2. Ethical approval for the study was obtained from the Faculty Deontological Commission and was conducted in compliance with the Declaration of Helsinki. Sociodemographic characteristics of the sample are depicted in Table 2.

\section{Measures}

Sociodemographic Characteristics Participants provided information about their age, gender, civil status, educational level, current economic activity, gross annual household income, household composition and their history of mental health difficulties.

Three-Item Loneliness Scale (TILS; Hughes et al., 2004) was specifically used to measure perception of social connectedness. Respondents were asked how often they felt that they: (1) lacked companionship; (2) were left out; and (3) were

Table 1 English and Spanish items version of the Three-Item Loneliness Scale (TILS)

Item

How often do you feel that you lack companionship? [¿Con qué frecuencia sientes que te falta compañía?]

How often do you feel left out?

[¿Con qué frecuencia te sientes excluido?]

How often do you feel isolated from others?

[¿Con qué frecuencia te sientes aislado de los demás?] 
Table 2 Sociodemographic characteristics of the sample

\begin{tabular}{lc}
\hline & $\begin{array}{c}\text { Participants } \\
(N=1951)\end{array}$ \\
\hline Gender $[n(\%)]$ Female & $921(47.2)$ \\
Age [Mean (SD, range)] & $45.16(12.78,18-75)$ \\
Civil Status $[n(\%)]$ & \\
Single & $778(40)$ \\
Married / Unmarried couple & $1001(51.4)$ \\
Separated / Divorced / Widower & $168(8.6)$ \\
Educational level $[n(\%)]$ & \\
No formal education / Primary & $61(3.1)$ \\
Secondary / High School & $622(31.9)$ \\
Vocational training & $292(15)$ \\
University graduate & $976(50)$ \\
Current economic activity $[n(\%)]$ & \\
Unemployed & $333(17.1)$ \\
Retired / With disability / Part time job & $187(9.6)$ \\
Student & $110(5.6)$ \\
Employed & $1321(67.7)$ \\
Gross annual household income in euros, 2019 $[n(\%)]$ \\
12,450-20,200 \\
20,200-35,200 & $694(35.6)$ \\
$35,200-60,000$ & $673(34.5)$ \\
Over 60,000 & $456(23.4)$ \\
Household composition $[n(\%)]$ & $128(6.6)$ \\
Living alone & $257(13.2)$ \\
Living without children & $1163(59.6)$ \\
History of mental health difficulties $[n(\%)]$ & \\
Never received treatment & $1533(78.6)$ \\
Received treatment & $277(14.2)$ \\
Currently receiving treatment & \\
\hline & \\
& \\
&
\end{tabular}

isolated from others, on a 3-point Likert scale coded from 1 'hardly ever', to 3 'often'. Individuals' responses were summed up, with higher scores indicating greater loneliness (range from 3 to 9). In this study, the Cronbach's alpha was $\operatorname{good}(\alpha=0.82)$.

Perception of belonging scale was used to assess the respondent's level of belongingness and connectedness to their neighbourhood and neighbours on a 4-point Likert scale. The scale had three items adapted from the UK Community Life Survey (Cabinet Office, 2015). A total score is obtained by calculating the average of these items, whose Cronbach alpha was good in this study $(\alpha=0.80)$.

Mistrust of Institutions Respondents were asked the extent to which they have trust in the following institutions: (1) political parties; (2) parliament; (3) the government; (4) the police; (5) the legal system; (6) scientists; and (7) doctors and other health professionals, on a 5-point Likert scale. A total mistrust score is obtained by calculating the items score average. In this study, the Cronbach's alpha was acceptable $(\alpha=0.77)$.

Mistrust of Others One item to evaluate to what extent individuals would mistrust most people on a 5-point Likert scale.

Short-Form Persecution and Deservedness Scale (SF-PaDS; Elahi et al., 2017) is a 5-item instrument to assess suspiciousness in clinical and general population samples that has been validated in Spanish with good psychometric properties (Valiente et al., 2020). Participants rate their agreement on a 5 -point scale. By adding up the scores, an overall score is obtained. In this study Cronbach's alpha was good $(\alpha=0.85)$.

The Patient Health Questionnaire-9 (PHQ-9; Kroenke \& Spitzer, 2002) is a 9-item scale to asses depressive symptoms, over the previous two weeks, on a 4-point Likert scale. A total score is obtained by adding all items. It has been validated in Spanish with good psychometric properties (Diez-Quevedo et al., 2001). In this study, the Cronbach's alpha was good $(\alpha=0.89)$.

The Generalised Anxiety Disorder Scale (GAD-7; Spitzer et al., 2006) is a 7-item scale to measure how often, in the previous 7 days, participants were bothered by anxiety symptoms listed on a 4-point Likert scale. A total score is obtained by adding all items. As in the Spanish validation by GarcíaCampayo et al. (2010), in this study the Cronbach's alpha was excellent $(\alpha=0.93)$.

\section{The Pemberton Happiness Index}

(PHI; Hervás \& Vázquez, 2013) was used as a measure of positive mental health. The PHI includes 11 retrospective items related to 'remembered well-being' (i.e., general hedonic, eudaimonic and social well-being) on an 11-point Likert scale. In this study the Cronbach's alpha was excellent ( $\alpha=$ 0.93).

\section{Data Analysis}

To explore the factorial structure of the TILS, the three items were subjected to a Principal Components Analysis (PCA) and the decision regarding the number of factors to extract was made also using both $\mathrm{K}=1$ criteria and Parallel Analysis method (Hayton et al., 2004). Regarding psychometric properties, internal consistency reliability and Test-retest reliability were analysed, by calculating Cronbach's alpha $(\alpha)$, and by estimating the intraclass correlation coefficient (ICC) with $95 \%$ CI between the two administrations of the test, respectively. We examined the convergent validity of the scale by using the bivariate correlation analysis with the other related variables. Finally, to analyse the differences in the 
TILS scores according to gender and age, as well as education, income, employment status and history of mental health difficulties, a two-way between-groups and one-way analyses of variance were carried out. Analyses were conducted using the SPSS 23 program.

\section{Results}

\section{The Structure of TILS. Principal Components Factor Analysis (PCA)}

Prior to performing the PCA, the suitability of data for factor analysis was assessed. Inspection of the correlation matrix of TILS items revealed that all coefficients were well above 0.3. The Kaiser-Meyer-Olkin value (Kaiser, 1974) was 0.68, exceeding the recommended value of 0.6 and Bartlett's test of sphericity (Bartlett, 1954) was also significant, $X^{2}=2309.72$, $p<.001$. PCA and Parallel Analysis showed the presence of a single factor that would explain $73.86 \%$ of the total variance. The screen-plot revealed a clear break after the first component and confirmed the unifactorial structure of the TILS. Finally, all the elements had high saturations in the loneliness factor with the following values (item $1=0.795$; item $2=$ 0.880 ; item $3=0.899$ ).

\section{Psychometric Properties of the TILS Scale}

Cronbach's alpha coefficient revealed that the internal consistency of the TILS scale was good. And the inter-item correlation matrix ( $r$ between .52 and .73) showed that there was no redundancy among the test items. The alpha value of the total scale does not increase if any item were eliminated (see Table 7). According to Koo and Li (2016), the test-retest intraclass correlation coefficient was good (ICC $=.83$ ).

Regarding convergent validity TILS showed moderate, positive and negative correlations $(r>.40)$ with mental health outcomes, while it revealed mild correlation with Belongingness, Mistrust of others and Mistrust of institutions (see Table 4).

Furthermore, we have assessed the sensitivity to change by construct validation following the guidelines of De Vet et al. (2011). First, we calculated the change score of the TILS, PHQ-9 and GAD-7 by subtracting T2 by T1 scores and then we correlated their change scores. As expected, they were positive and significant correlations between the TILS and GAD-7 $(r=.14)$, and the TILS and PHQ-9 change scores $(r=.14)$ which is indicative of an appropriate sensitivity.

\section{Loneliness and Sociodemographic Variables}

Table 5 shows the means and standard deviations of the TILS scores according to sociodemographic characteristics. After dividing participants into six groups by age (see Table 3), the analysis of variance showed a statically significant main effect for gender, $F(1,1951)=22.03, p<.01$ and for age $F(5$, $1951)=14.98, p<.01$; with a small size effect $\left(\eta_{\mathrm{p}}{ }^{2} \leq .04\right)$ for both variables, although, the interaction effect between gender and age group did not reach significance $(p=.06)$. Post-hoc comparisons using the Bonferroni test indicated that, the mean score of loneliness for the youngest age group and the group between 25 and 34 years were significantly higher than for the rest of the age groups, and that the mean score for the female group was significantly higher than for males.

In relation to the educational level, a univariate ANOVA revealed that there were significant differences in the TILS scores, $F(3,1951)=3.28, p=.02$, with a small effect size $\left(\mathrm{y}_{\mathrm{p}}{ }^{2}=.01\right)$. Post-hoc analysis (T3 Dunnet) indicated that participants with a vocational training had higher loneliness scores than people with a university degree.

Regarding the annual income, analysis revealed significant differences in the TILS scores, $F(3,1951)=30.68, p<.001$, with a small effect size $\left(\mathrm{y}_{\mathrm{p}}{ }^{2}=.04\right)$. Post-hoc analysis $(\mathrm{T} 3$ Dunnet) indicated that the TILS scores of participants with the least and medium income were significantly higher than those with the highest income $(p<.01)$.

With regard to the employment status, results showed that the TILS scores were statistically different in relation to different work situations $F(3,1951)=18.68, p<.001$, with a small effect size $\left(\mathrm{y}_{\mathrm{p}}{ }^{2}=.03\right)$. Post-hoc analysis (T3 Dunnet) revealed that respondents in situations of unemployed or students had significantly higher loneliness scores than those in situations of employment, retired or with a disability ( $p$ $<.001)$.

In consideration household composition, analysis showed that the TILS scores were statistically different between both groups $F(1,1951)=13.94, p<.001$, with a small effect size $\left(\mathrm{n}_{\mathrm{p}}{ }^{2}<0.01\right)$. Post-hoc analysis revealed that participants who lived alone had significantly higher loneliness scores than those who lived accompanied by other adults ( $p$ $<.001)$. There were also differences between those who live with children and those who do not $F(1,1951)=4.69$, $p=.03$, with a small effect size $\left(\mathrm{y}_{\mathrm{p}}{ }^{2}<.01\right)$. Post-hoc analysis revealed that participants who live without children experienced significantly higher loneliness levels than those who lived with children $(p<.001)$. Additionally, the results showed a significant main effect for mental health difficulties $F(1,1913)=50.20, p<.001$, with a small effect size $\left(\mathrm{y}_{\mathrm{p}}{ }^{2}=.05\right)$. Post-hoc analysis, revealed that people who are currently received treatment or had received in the past experience higher levels of loneliness, being even greater for those who are currently in treatment.

Finally, Table 6 shows the percentiles corresponding to the total score in the TILS for groups of age and gender. Meanwhile, Table 7 shows the percentage distribution of the TILS intervals according to gender and age. 
Table 3 Sample distribution (\%) for each TILS item and psychometric properties $(N=1951)$

123 Mean SD Kurtosis Asymmetry $\alpha$ when eliminating Items $r$ with the the item total score

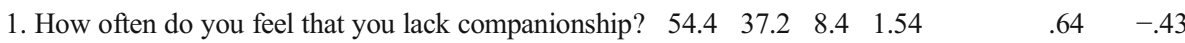

$81 * *$

2. How often do you feel left out?

$\begin{array}{llll}60.6 & 32.2 & 7.2 & 1.47\end{array}$

$.63-.06$

1.006

.72

$87 * *$

3. How often do you feel isolated from others?

$\begin{array}{llll}59.8 & 32.3 & 7.8 & 1.48\end{array}$

$.64-.13$

.98

.68

$.89 * *$

Total sample $(N=1951)$ distribution (\%) for each TILS item and psychometric properties

Note. $* * p<0.01$

\section{Discussion}

To our knowledge, this is the first study that validates the TILS in a representative and large sample of Spanish adults. Our findings, supporting a unifactorial structure, are in line with the original publication of the scale (Hughes et al., 2004) and other translated versions (Igarashi, 2019).

In our study, the prevalence of loneliness was slightly higher than in previous European studies (Lasgaard et al., 2016). In this regard, we found that $5.8 \%$ of the sample often experienced feelings of loneliness and $22.2 \%$ experienced them at times. Furthermore, our total sample reported higher levels of loneliness than those reported by the authors of the original scale (Hughes et al., 2004), who noted that loneliness is sensitive to demographic and social changes. We believe that this higher incidence may be associated with the circumstances during the launching of the survey, in the midst of the COVID-19 pandemic with forced confinement measures.

Table 4 Mean, Standard Deviation and Bivariate Pearson correlations analysis between Three-Item Loneliness Scale (TILS) score and other instruments used

\begin{tabular}{llll}
\hline & $M$ & $S D$ & Pearson $r$ \\
\hline Belongingness in neighbourhood & 2.66 & 0.79 & $-.25^{* *}$ \\
Mistrust of others & 3.13 & 1.05 & $.17^{* *}$ \\
Mistrust of institution & 3.12 & 0.63 & $.16^{* *}$ \\
Paranoia & 5.96 & 4.43 & $.43^{* *}$ \\
Depression & 6.50 & 5.65 & $.52^{* *}$ \\
Anxiety & 5.86 & 5.24 & $.42^{* *}$ \\
Well-being & 7.12 & 1.59 & $-.53^{* *}$ \\
\hline
\end{tabular}

Note. $* * p<0.01$
Regarding the psychometric properties, the results show that the scale has a good internal consistency, higher than the original publication and very similar to the Japanese version. The high correlation of each individual item with the total score also confirms a good internal consistency of the scale. Our results also indicate that TILS is a stable measure, with a good test-rest. In relation to convergent validity, the TILS has shown to be moderately correlated with several negative mental health outcomes. This is consistent with previous literature that suggested a relationship between loneliness and depression (Domènech-Abella et al., 2019;), anxiety (Boehlen et al., 2020) and paranoia (Lamster, Nittel, et al., 2017b). In line with the socio-cognitive model of loneliness (Cacioppo \& Hawkley, 2005) that associates loneliness with dysfunctional attributions and appraisals of other people (Jones et al., 1981), and with a lack of interpersonal trust (Rotenberg et al., 2010), we found associations of loneliness with mistrust of others and institutions as well as sense of belonging. Mellor et al. (2008) also reported a strong correlation between loneliness and the unmet need for belonging. Finally, the results showed a high negative correlation between loneliness and well-being which is consistent with the literature (e.g. Musich et al., 2015) and indicates the weight of this issue in positive as well as negative psychological health. Seligman (2011) identifies having healthy relationships with others as a key element of well-being and our results consistently indicate that its absence is clearly associated with lower levels of happiness.

Considering the demographic distribution of TILS scores, and although the effect sizes were small, our findings showed that females, young people, students and college graduates, those with lower annual income, people in situations of 
Table 5 Means and standard deviations of the Three-Item Loneliness Scale (TILS) scores according to gender, age, education, income, employment, household composition and mental health difficulties

\begin{tabular}{|c|c|c|c|c|c|c|c|c|c|}
\hline & \multicolumn{3}{|l|}{ Male } & \multicolumn{3}{|c|}{ Female } & \multicolumn{3}{|l|}{ Total } \\
\hline & Mean & $S D$ & $N$ & Mean & $S D$ & $N$ & Mean & $S D$ & $N$ \\
\hline \multicolumn{10}{|l|}{ Age } \\
\hline $18-24$ & 4.91 & 1.80 & 66 & 5.69 & 1.85 & 90 & 5.36 & 1.87 & 156 \\
\hline $25-34$ & 4.79 & 1.82 & 135 & 4.93 & 1.71 & 138 & 4.86 & 1.76 & 273 \\
\hline $35-44$ & 4.32 & 1.52 & 248 & 4.69 & 1.75 & 221 & 4.49 & 1.64 & 469 \\
\hline $45-54$ & 4.23 & 1.41 & 305 & 4.43 & 1.67 & 214 & 4.31 & 1.52 & 519 \\
\hline $55-64$ & 4.19 & 1.31 & 211 & 4.25 & 1.60 & 216 & 4.22 & 1.46 & 427 \\
\hline $65+$ & 3.74 & 1.25 & 65 & 4.62 & 1.81 & 42 & 4.08 & 1.55 & 107 \\
\hline \multicolumn{10}{|l|}{ Household Income } \\
\hline $12,450-20,200$ & 4.73 & 1.73 & 316 & 5.01 & 1.79 & 378 & 4.88 & 1.77 & 694 \\
\hline $20,200-35,200$ & 4.29 & 1.46 & 356 & 4.66 & 1.69 & 317 & 4.47 & 1.59 & 673 \\
\hline $35,200-60,000$ & 4.08 & 1.29 & 276 & 4.12 & 1.61 & 180 & 4.09 & 1.42 & 456 \\
\hline$>60,000$ & 3.78 & 1.22 & 82 & 3.89 & 1.51 & 46 & 3.82 & 1.32 & 128 \\
\hline \multicolumn{10}{|l|}{ Educational level } \\
\hline Without Studies / Primary & 4.47 & 1.79 & 32 & 4.31 & 1.47 & 29 & 4.39 & 1.64 & 61 \\
\hline Secondary / High School & 4.39 & 1.53 & 330 & 4.71 & 1.86 & 292 & 4.54 & 1.69 & 622 \\
\hline Vocational training & 4.43 & 1.55 & 148 & 4.99 & 1.82 & 144 & 4.71 & 1.71 & 292 \\
\hline University graduate & 4.25 & 1.48 & 520 & 4.55 & 1.66 & 456 & 4.39 & 1.57 & 976 \\
\hline \multicolumn{10}{|l|}{ Current economic activity } \\
\hline Unemployed & 4.91 & 1.87 & 114 & 4.71 & 1.76 & 219 & 4.78 & 1.79 & 333 \\
\hline Retired / With disability & 3.92 & 1.28 & 111 & 4.78 & 1.92 & 76 & 4.27 & 1.62 & 187 \\
\hline Student & 4.91 & 1.95 & 45 & 5.72 & 1.82 & 65 & 5.39 & 1.91 & 110 \\
\hline Employed & 4.27 & 1.43 & 760 & 4.50 & 1.67 & 561 & 4.37 & 1.54 & 1321 \\
\hline \multicolumn{10}{|l|}{ Household composition } \\
\hline Living alone & 4.60 & 1.50 & 123 & 5.06 & 1.84 & 134 & 4.84 & 1.70 & 257 \\
\hline Living with one or more adults & 4.29 & 1.52 & 907 & 4.59 & 1.73 & 787 & 4.43 & 1.62 & 1694 \\
\hline Living without children & 4.40 & 1.57 & 610 & 4.71 & 1.76 & 553 & 4.55 & 1.67 & 1163 \\
\hline Living with children & 4.22 & 1.42 & 420 & 4.58 & 1.73 & 368 & 4.39 & 1.59 & 788 \\
\hline \multicolumn{10}{|c|}{ History of mental health difficulties } \\
\hline Never received treatment & 4.24 & 1.46 & 864 & 4.37 & 1.56 & 666 & 4.29 & 1.51 & 1530 \\
\hline Received treatment & 4.59 & 1.57 & 100 & 5.28 & 1.91 & 165 & 5.02 & 1.82 & 265 \\
\hline Currently receiving treatment & 5.13 & 1.89 & 53 & 5.81 & 2.07 & 66 & 5.51 & 2.01 & 119 \\
\hline
\end{tabular}

Table 6 Three-Item Loneliness Scale (TILS) percentiles according to gender and age. $N=1951$

\begin{tabular}{|c|c|c|c|c|c|c|c|c|c|c|c|c|c|}
\hline \multirow[b]{2}{*}{$\mathrm{Pc}$} & \multicolumn{2}{|l|}{$18-24$} & \multicolumn{2}{|l|}{$25-34$} & \multicolumn{2}{|c|}{$35-44$} & \multicolumn{2}{|c|}{$45-54$} & \multicolumn{2}{|l|}{$55-64$} & \multicolumn{2}{|l|}{$65+$} & \multirow[t]{2}{*}{ Total } \\
\hline & Male & Female & Male & Female & Male & Female & Male & Female & Male & Female & Male & Female & \\
\hline 100 & 9 & 9 & 9 & 9 & 9 & 9 & 9 & 9 & 9 & 9 & 8 & 9 & 9 \\
\hline 90 & 8 & 9 & 8 & $7-8$ & $6-8$ & $7-8$ & $6-8$ & $7-8$ & $6-8$ & $6-8$ & $6-7$ & $7-8$ & 7 \\
\hline 80 & $6-7$ & $7-8$ & $6-7$ & 6 & 6 & 6 & 6 & 6 & $5.6-6$ & 6 & 5 & 6 & 6 \\
\hline 70 & 6 & 6 & 6 & 6 & 5 & 6 & 5 & 5 & 5 & 5 & 4 & 6 & 5 \\
\hline 60 & 5 & 6 & 5 & 5.4 & 4 & 5 & 4 & 4 & 4 & 4 & 3 & $4.8-5$ & 5 \\
\hline 50 & $4.5-5$ & 6 & 4 & 5 & 4 & 4 & 4 & 4 & 4 & 4 & 3 & 4 & 4 \\
\hline 40 & 4 & 5 & 4 & 4 & 3 & 4 & 3 & 3 & 3 & 3 & 3 & 4 & 3 \\
\hline 30 & 4 & 4 & 3 & 3 & 3 & 3 & 3 & 3 & 3 & 3 & 3 & 3 & 3 \\
\hline 20 & 3 & 4 & 3 & 3 & 3 & 3 & 3 & 3 & 3 & 3 & 3 & 3 & 3 \\
\hline 10 & 3 & 3 & 3 & 3 & 3 & 3 & 3 & 3 & 3 & 3 & 3 & 3 & 3 \\
\hline 1 & 3 & 3 & 3 & 3 & 3 & 3 & 3 & 3 & 3 & 3 & 3 & 3 & 3 \\
\hline$N$ & 66 & 90 & 135 & 138 & 248 & 221 & 305 & 214 & 211 & 216 & 65 & 42 & 1951 \\
\hline Mean & 4.91 & 5.69 & 4.79 & 4.93 & 4.32 & 4.69 & 4.23 & 4.43 & 4.19 & 4.25 & 3.74 & 4.62 & 4.48 \\
\hline$S D$ & 1.80 & 1.85 & 1.82 & 1.71 & 1.52 & 1.75 & 1.41 & 1.67 & 1.31 & 1.60 & 1.25 & 1.81 & 1.63 \\
\hline
\end{tabular}

Note. $\mathrm{SD}=$ Standard Deviation $; P C=$ percentile 
Table 7 Percentage Distribution $(\%)$ of the total sample $(N=1951)$ in the different Three-Item Loneliness Scale (TILS) intervals according to gender and age

\begin{tabular}{|c|c|c|c|c|c|c|c|c|c|c|c|c|c|c|c|}
\hline \multirow[b]{2}{*}{ Score Intervals } & \multicolumn{2}{|l|}{$18-24$} & \multicolumn{2}{|l|}{$25-34$} & \multicolumn{2}{|l|}{$35-44$} & \multicolumn{2}{|l|}{$45-54$} & \multicolumn{2}{|l|}{$55-64$} & \multicolumn{2}{|l|}{$65+$} & \multicolumn{2}{|l|}{ Total } & \multirow[b]{2}{*}{ Total } \\
\hline & Male & Female & Male & Female & Male & Female & Male & Female & Male & Female & Male & Female & Male & Female & \\
\hline $\begin{array}{l}\text { Hardly Ever } \\
(3-5)\end{array}$ & $62.1 \%$ & $43.3 \%$ & $65.2 \%$ & $60.1 \%$ & $77.4 \%$ & $67.9 \%$ & $77.7 \%$ & $71.5 \%$ & $80.1 \%$ & $76.4 \%$ & $87.7 \%$ & $69.0 \%$ & $76.1 \%$ & $67.2 \%$ & $71.9 \%$ \\
\hline $\begin{array}{l}\text { Some of the Time } \\
(6-7)\end{array}$ & $27.3 \%$ & $38.9 \%$ & $23.7 \%$ & $31.9 \%$ & $19.4 \%$ & $24.4 \%$ & $20.0 \%$ & $22.4 \%$ & $18.5 \%$ & $17.6 \%$ & $10.8 \%$ & $23.8 \%$ & $19.9 \%$ & $24.9 \%$ & $22.2 \%$ \\
\hline Often $(8-9)$ & $10.6 \%$ & $17.8 \%$ & $11.1 \%$ & $8.0 \%$ & $3.2 \%$ & $7.7 \%$ & $2.3 \%$ & $6.1 \%$ & $1.4 \%$ & $6.0 \%$ & $1.5 \%$ & $7.1 \%$ & $4.0 \%$ & $7.9 \%$ & $5.8 \%$ \\
\hline
\end{tabular}

unemployed, and those with a history of mental health difficulties seemed to experience more loneliness. In line with previous literature, sociodemographic variables are important risk factors associated with loneliness (Beutel et al., 2017). Contrary the findings of Vozikaki et al. (2018), our results support a nonlinear U-shaped distribution for loneliness in relation with age (Victor \& Yang, 2012). Moreover, our results showed that the household composition was a good predictor of loneliness and that those who lived alone and without children experienced it more.

The present study presents a number of strengths and limitations. The fact that we used a large and representative sample, in highly controlled methodological conditions and using a brief questionnaire that can be used in population surveys adds value to the study. We also provided the normative data in a representative sample of Spaniards. Finally, we were able to report the test-retest validity because we had two evaluation points. Regarding the limitations, the sample was recruited during the COVID-19 pandemic and thus, their isolation scores could be inflated by the sense of threat and the confinement associated to this pandemic. Furthermore, we only use self-report measures, social desirability biases cannot be ruled out, and it would have been interesting to include an objective measure of social isolation. Lastly, while one of the strengths of this study is the representativeness of the sample, the fact that it is an online study may reduce it, particularly among older respondents.

In conclusion, the results of this study showed that the Spanish version of TILS has good psychometric properties for measuring loneliness quickly, with the advantage of reducing the burden of long questionnaires. Loneliness is considered a modern epidemic as well as a precursor of health problems that needs the attention of health professionals (Campagne, 2019). For this purpose, it is important to have a reliable and validated measure, which could allow a quick screening in risk populations (e.g. youth and elderly people, people with depression, health problems, etc) that could be used in Spain and other Spanish speaking countries.
Acknowledgments This research was supported by grants from the Ministry of Science and Innovation [PSI2016-74987-P], Instituto Carlos III (COV20/00737-CM) and funds from the UCM for consolidated research groups (GR29/20). Almudena Trucharte had an UCM doctoral fellowship (CT42/18) and Vanesa Peinado had a Ministry of Economy and Competitiveness doctoral Fellowship (BES-2017082015). We also thank Jamie O'Grady for his help in editing the paper.

Code Availability Not applicable.

Author Contributions All authors contributed to the study conception and design. Material preparation and data collection were performed by Almudena Trucharte, Alba Contreras and Vanesa Peinado. Analysis were carried out by Lara Calderon and Almudena Trucharte. The first draft of the manuscript was written by Almudena Trucharte, Elena Cerezo and all authors commented on previous versions of the manuscript. The manuscript was supervised by Carmen Valiente. All authors read and approved the final manuscript.

Funding This research was supported by grants from the Ministry of Science and Innovation [PSI2016-74987-P], Instituto Carlos III (COV20/00737-CM) and funds from the UCM for consolidated research groups (GR29/20).

Data Availability The project was registered in Open Science Framework (OSF). For more detailed description https://osf.io/2y45r

\section{Declarations}

Conflict of Interest None of the authors who sign this paper has any conflict of interest in the conduct and reporting of our research.

\section{References}

Algren, M. H., Ekholm, O., Nielsen, L., Ersbøll, A. K., Bak, C. K., \& Andersen, P. T. (2020). Social isolation, loneliness, socioeconomic status, and health-risk behaviour in deprived neighbourhoods in Denmark: A cross-sectional study. SSM-population health, 10, 100546. https://doi.org/10.1037/10808-001.

Bartlett, M. S. (1954). A note on the multiplying factors for various $\chi 2$ approximations. Journal of the Royal Statistical Society: Series B (Methodological), 16(2), 296-298.

Berg-Weger, M., \& Morley, J. E. (2020). Loneliness in old age: An unaddressed health problem. Journal of Nutrition, Health and Aging, 24(3), 243-245. 
Beutel, M. E., Klein, E. M., Brähler, E., Reiner, I., Jünger, C., Michal, M., Wiltink, J., Wild, P. S., Münzel, T., Lackner, K. J., \& Tibubos, A. N. (2017). Loneliness in the general population: Prevalence, determinants and relations to mental health. BMC Psychiatry, 17(1), 97.

Boehlen, F. H., Herzog, W., Schellberg, D., Maatouk, I., Schoettker, B., Brenner, H., \& Wild, B. (2020). Gender-specific predictors of generalized anxiety disorder symptoms in older adults: Results of a large population-based study. Journal of Affective Disorders, 262, 174-181.

Cabinet Office. (2015). Community life survey technical report 2014-15. Retrieved from https://assets.publishing.service.gov.uk/ government/uploads/system/uploads/attachment_data/file/470407/ Community_Life_2014-15_Combined_technical_report_FINAL. pdf

Cacioppo, J. T., \& Hawkley, L. C. (2005). People Thinking About People: The Vicious Cycle of Being a Social Outcast in One's Own Mind. In K. D. Williams, J. P. Forgas, \& W. von Hippel (Eds.), The social outcast: Ostracism, social exclusion, rejection, and bullying (pp. 91-108). Psychology Press.

Campagne, D. M. (2019). Stress and perceived social isolation (loneliness). Archives of Gerontology and Geriatrics, 82, 192-199.

Chau, A. K. C., Zhu, C., \& So, S. H. W. (2019). Loneliness and the psychosis continuum: A meta-analysis on positive psychotic experiences and a meta-analysis on negative psychotic experiences. International Review of Psychiatry, 31, 471-490.

De Vet, H. C., Terwee, C. B., Mokkink, L. B., \& Knol, D. L. (2011). Measurement in medicine: a practical guide. Cambridge university press.

Diez-Quevedo, C., Rangil, T., Sanchez-Planell, L., Kroenke, K., \& Spitzer, R. L. (2001). Validation and utility of the patient health questionnaire in diagnosing mental disorders in 1003 general hospital Spanish inpatients. Psychosomatic Medicine, 63(4), 679-686.

Domènech-Abella, J., Mundó, J., Leonardi, M., Chatterji, S., TobiaszAdamczyk, B., Koskinen, S., Ayuso-Mateos, J. L., Haro, J. M., \& Olaya, B. (2019). Loneliness and depression among older European adults: The role of perceived neighborhood built environment. Health and Place, 62, 102280.

Elahi, A., Perez Algorta, G., Varese, F., McIntyre, J. C., \& Bentall, R. P. (2017). Do paranoid delusions exist on a continuum with subclinical paranoia? A multi-method taxometric study. Schizophrenia Research, 190, 77-81.

Erzen, E., \& Çikrikci, Ö. (2018). The effect of loneliness on depression: A meta-analysis. International Journal of Social Psychiatry, 64(5), 427-435.

García-Campayo, J., Zamorano, E., Ruiz, M. A., Pardo, A., PérezPáramo, M., López-Gómez, V., et al. (2010). Cultural adaptation into Spanish of the generalized anxiety disorder-7 (GAD-7) scale as a screening tool. Health and Quality of Life Outcomes, 8(1), 8.

Greenaway, K. H., Haslam, S. A., \& Bingley, W. (2019). Are "they" out to get me? A social identity model of paranoia. Group Processes and Intergroup Relations, 22(7), 984-1001.

Haworth, K., Kanter, J. W., Tsai, M., Kuczynski, A. M., Rae, J. R., \& Kohlenberg, R. J. (2015). Reinforcement matters: A preliminary, laboratory-based component-process analysis of functional analytic Psychotherapy's model of social connection. Journal of Contextual Behavioral Science, 4(4), 281-291.

Hayton, J. C., Allen, D. G., \& Scarpello, V. (2004). Factor retention decisions in exploratory factor analysis: A tutorial on parallel analysis. Organizational Research Methods, 7(2), 191-205.

Hervás, G., \& Vázquez, C. (2013). Construction and validation of a measure of integrative well-being in seven languages: The Pemberton Happiness Index. Health and Quality of Life Outcomes, 11(1), 1-13.

Holt-Lunstad, J., Smith, T. B., Baker, M., Harris, T., \& Stephenson, D. (2015). Loneliness and social isolation as risk factors for mortality:
A meta-analytic review. Perspectives on Psychological Science, 10(2), 227-237.

Hughes, M. E., Waite, L. J., Hawkley, L. C., \& Cacioppo, J. T. (2004). A short scale for measuring loneliness in large surveys: Results from two population-based studies. Research on Aging, 26(6), 655-672. https://doi.org/10.1177/0164027504268574

Igarashi, T. (2019). Development of the Japanese version of the threeitem loneliness scale. BMC Psychology, 7(1), 1-8. https://doi.org/ 10.1186/s40359-019-0285-0.

Jones, W. H., Freemon, J. E., \& Goswick, R. A. (1981). The persistence of loneliness: Self and other determinants. Journal of Personality, 49(1), 27-48.

Kaiser, H. F. (1974). An index of factorial simplicity. Psychometrika, 39(1), 31-36.

Koo, T. K., \& Li, M. Y. (2016). A guideline of selecting and reporting Intraclass correlation coefficients for reliability research. Journal of Chiropractic Medicine, 15(2), 155-163.

Kroenke, K., \& Spitzer, R. L. (2002). The PHQ-9: A new depression diagnostic and severity measure. Psychiatric Annals, 32, 1-7. https://doi.org/10.3928/0048-5713-20020901-06.

Lamster, F., Lincoln, T. M., Nittel, C. M., Rief, W., \& Mehl, S. (2017a). The lonely road to paranoia. A path-analytic investigation of loneliness and paranoia. Comprehensive Psychiatry, 74, 35-43.

Lamster, F., Nittel, C., Rief, W., Mehl, S., \& Lincoln, T. (2017b). The impact of loneliness on paranoia: An experimental approach. Journal of Behavior Therapy and Experimental Psychiatry, 54, $51-57$.

Lasgaard, M., Friis, K., \& Shevlin, M. (2016). "Where are all the lonely people?" a population-based study of high-risk groups across the life span. Social Psychiatry and Psychiatric Epidemiology, 51(10), 1373-1384.

Lim, L. L., \& Kua, E. H. (2011). Living alone, loneliness, and psychological well-being of older persons in Singapore. Current Gerontology and Geriatrics Research, 2011, 1-9.

Lim, M. H., Rodebaugh, T. L., Zyphur, M. J., \& Gleeson, J. F. M. (2016). Loneliness over time: The crucial role of social anxiety. Journal of Abnormal Psychology, 125(5), 620-630.

Luhmann, M., \& Hawkley, L. C. (2016). Age differences in loneliness from late adolescence to oldest old age. Developmental Psychology, 52(6), 943-959.

Maes, M., Qualter, P., Vanhalst, J., Van den Noortgate, W., \& Goossens, L. (2019). Gender differences in loneliness across the lifespan: A meta-analysis. European Journal of Personality, 33(6), 642-654.

McIntyre, J. C., Wickham, S., Barr, B., \& Bentall, R. P. (2018). Social identity and psychosis: Associations and psychological mechanisms. Schizophrenia Bulletin, 44(3), 681-690.

Mellor, D., Stokes, M., Firth, L., Hayashi, Y., \& Cummins, R. (2008). Need for belonging, relationship satisfaction, loneliness, and life satisfaction. Personality and Individual Differences, 45(3), 213218.

Meltzer, H., Bebbington, P., Dennis, M. S., Jenkins, R., McManus, S., \& Brugha, T. S. (2013). Feelings of loneliness among adults with mental disorder. Social Psychiatry and Psychiatric Epidemiology, 48(1), 5-13.

Mushtaq, R., Shoib, S., Shah, T., \& Mushtaq, S. (2014). Relationship between loneliness, psychiatric disorders and physical health? A review on the psychological aspects of loneliness. Journal of Clinical and Diagnostic Research: JCDR, 8(9), WE01. https://doi. org/10.7860/JCDR/2014/10077.4828.

Musich, S., Wang, S. S., Hawkins, K., \& Yeh, C. S. (2015). The impact of loneliness on quality of life and patient satisfaction among older, sicker adults. Gerontology and Geriatric Medicine, 1-9. https://doi. org/10.1177/2333721415582119.

Peplau, L. A., \& Perlman, D. (1982). Perspectives on loneliness. In L. A. Peplau \& D. Perlman (Eds.), Loneliness: A sourcebook of current theory, research and therapy (pp. 1-18). Wiley. 
Rotenberg, K. J., Addis, N., Betts, L. R., Corrigan, A., Fox, C., Hobson, Z., Rennison, S., Trueman, M., \& Boulton, M. J. (2010). The relation between trust beliefs and loneliness during early childhood, middle childhood, and adulthood. Personality and Social Psychology Bulletin, 36(8), 1086-1100.

Russell, D., Peplau, L. A., \& Ferguson, M. L. (1978). Developing a measure of loneliness. Journal of Personality Assessment, 42(3), 290-294.

Sancho, P., Pinazo-Hernandis, S., Donio-Bellegarde, M., \& Tomás, J. M. (2020). Validation of the University of California, Los Angeles loneliness scale (version 3) in Spanish older population: An application of exploratory structural equation modelling. Australian Psychologist, 55(3), 283-292.

Seligman, M. E. (2011). Flourish: a visionary new understanding of happiness and well-being. Policy, 27(3), 60-1.

Spitzer, R. L., Kroenke, K., Williams, J. B. W., \& Löwe, B. (2006). A brief measure for assessing generalized anxiety disorder: The GAD-7. Archives of Internal Medicine, 166(10), 1092-1097.

Steed, L., Boldy, D., Grenade, L., \& Iredell, H. (2007). The demographics of loneliness among older people in Perth, Western Australia: Research. Australasian Journal on Ageing, 26(2), 81-86.

Valiente, C., Contreras, A., Trucharte, A., Peinado, V., \& Espinosa, R. (2020). Psychometric properties and normative data of the Spanish version of short form persecution and deservedness scale. Psychosis, 1-13. https://doi.org/10.1080/17522439.2020.1834605.

Valtorta, N. K., Kanaan, M., Gilbody, S., Ronzi, S., \& Hanratty, B. (2016). Loneliness and social isolation as risk factors for coronary heart disease and stroke: systematic review and meta-analysis of longitudinal observational studies. Heart, 102(13), 1009-1016. https://doi.org/10.1136/heartjnl-2015-308790.

Victor, C. R., \& Yang, K. (2012). The prevalence of loneliness among adults: A case study of the United Kingdom. Journal of Psychology: Interdisciplinary and Applied, 146(1-2), 85-104.

Vozikaki, M., Papadaki, A., Linardakis, M., \& Philalithis, A. (2018). Loneliness among older European adults: Results from the survey of health, aging and retirement in Europe. Journal of Public Health (Germany), 26(6), 613-624.

Wang, J., Mann, F., Lloyd-Evans, B., Ma, R., \& Johnson, S. (2018). Associations between loneliness and perceived social support and outcomes of mental health problems: A systematic review. $B M C$ Psychiatry, 18(1), 1-16.

Yang, K., \& Victor, C. (2011). Age and loneliness in 25 European nations. Ageing and Society, 31(8), 1368-1388.

Publisher's Note Springer Nature remains neutral with regard to jurisdictional claims in published maps and institutional affiliations. 